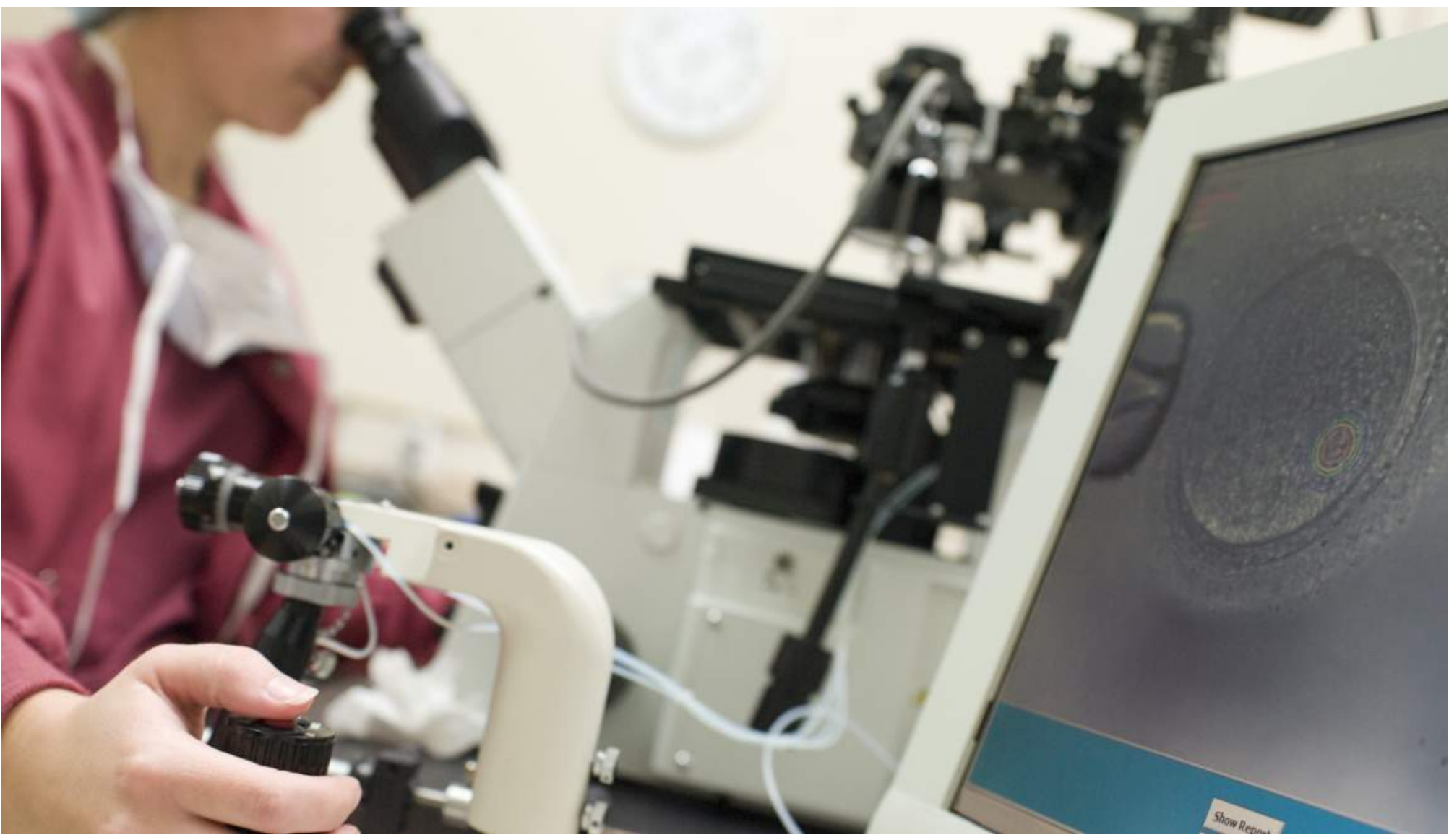

Commentary

\title{
Delisting Full Coverage for In Vitro
} Fertilization in Quebec

Alexia De Simone ${ }^{1}$

Published online: 25 November 2019

${ }^{1}$ Faculty of Medicine, McGill University, Montréal, Canada.

Corresponding Author: Alexia De Simone, email alexia.desimone@mail.mcgill.ca. 


\section{Abstract}

On November $10^{\text {th }}, 2015$, in creation of Bill 20, "An Act to promote access to family medicine and specialized medicine services and to amend various legislative provisions relating to assisted procreation," the Quebec government withdrew full coverage for its assisted procreation program which had been in place since 2010. The previously approved legislation under Bill 26 aimed to decrease costs associated from multiple-birth pregnancies and to increase the number of live-births in the province by funding up to six natural in vitro fertilization (IVF) cycles and implementing a single-embryo-transfer (SET) policy. IVF is a medical process where sperm and egg are brought together in a controlled laboratory setting and transferred into mother, whereas intrauterine insemination (IUI) is a process where sperm are injected into a woman's reproductive system. One factor that contributed to delisting IVF services in Quebec was Quebec's Commission of Health and Well-Being's report that concluded that IVF services costed $\$ 63$ million and resulted in 1300 births/per year. Taken within the larger context of Quebec's goal to optimize financial resources within the healthcare system and to reduce the province's growing debt, under Bill 20, the government withdrew fully-funded IVF services. The government imposed stricter criteria on who could access IVF, such as the woman's age and agreed to fund up to 9-cycles of IUI. Since implementation of Bill 20, IVF rates have dropped dramatically within the province as many individuals that cannot afford out-of-pocket costs for IVF. The newly elected government, the Coalition Avenir Quebec in 2018 is currently studying the possibility of reinstating full coverage for one IVF cycle by 2020.

Tags: In Vitro Fertilization, Delisting, Quebec, Bill 20, Tax-credits, Intra-uterine Insemination

\section{Terms and Important Concepts in Commentary}

In order to understand the consequences of this bill, it is important to understand the assisted reproduction technologies (ART): IVF and intra-uterine insemination (IUI). IVF is the medical process whereby sperm and egg cells are collected and brought together in a laboratory setting. Once an embryo is sufficiently developed, it is transferred into the mother (1). Medical procedures required for successful IVF include ovarian stimulation, eggretrieval, forming and storage of embryos, freezing and transfer of embryos. On the other hand, IUI, also known as 'artificial insemination,' consists of depositing treated sperm into the woman's reproductive system. Women may or may not receive adjunctive hormone stimulating medication during this treatment. Given that some women over-respond to drugs that stimulate ovulation during fertility treatments and that women may forgo counting the number of mature eggs in the uterus prior to IUI, IUI carries a greater risk than IVF for multiple gestational pregnancy. In IUI, the sperm cells come from a partner or a donor (1). Thus, multiple births are much more common with IUI than IVF (or natural conception).

\section{Brief Description of the Health Reform Policy}

On November 10th, 2015, the Quebec government passed, "An Act to promote access to family medicine and specialized medicine services and to amend various legislative provisions relating to assisted procreation" (2) in the National Assembly. While the majority of Bill 20 pertains to improving community access to family physicians in Quebec, the main legislative change of the Act discussed in this commentary is its withdrawal of financial coverage for in vitro fertilization (IVF), which had been previously funded under the Health Insurance Act of Bill 26 (See Section 2: History and Context of Leading to Implementation of Bill 20). 
Though withdrawing coverage for IVF, Bill 20 stated that up to nine cycles of artificial insemination treatments (IUI) would remain covered for women or couples with a medical diagnosis of infertility. As well, embryo storage until November 2018 would be covered for those already enrolled in the program until the end of their ovulation cycle. To establish a diagnosis of infertility according to Bill 20 , the treating physician must complete a basic medical report for the woman or couple, and make attempts to determine the cause of infertility via subsequent diagnostic tests. These include a standard physical exam, a basic pelvic ultrasound, and blood tests for hormone levels in women. In men, a sperm analysis and a sexually transmitted infection screen are performed. Following completion of these tests, the physician can recommend appropriate choice(s) of treatment (3).

Bill 20 also stipulated that oncology patients wishing to store eggs, sperm or embryos before cancer treatments would be fully insured if they wished to use their cryopreserved material for IVF in the future; although, if they had not chosen cryopreservation prior to oncology treatments, they could not access subsidized standard IVF later. The Quebec government further regulated said IVF treatments, and specified the number of embryos to be transferred per IVF treatment course - this is known as the single-embryo-transfer (SET) policy, which means that physicians are restricted to one embryo transfer at a time. However, if the woman is above 37 years-old, the physician may choose to transfer up to two embryos at once.

Other details regarding the bill include possible tax credit for out-of-pocket expenses related to IVF. Following the passing of the bill, on 10 November 2015, the Quebec Minister of Finance announced a tax credit (see Section 5.2 below) for a single IVF cycle for women younger than 37 and two cycles for women of the age of 37 and older. Conditions included that this would be the first access to IVF over the lifetime of the individual, and that neither parent had children or had been voluntarily sterilized (not having undergone tubal ligation or vasectomy).

Finally, Bill 20 also specified how the specialist physicians could manage fertility clinics: the director of an assisted procreation center must hold a specialist's certificate in reproductive and infertility gynecological endocrinology. Note that this commentary will not focus on this part of the bill. Please visit the following website for more details on the parliamentary proceedings and official law pertaining to those aspects of Bill 20.

\section{History and Context leading to Implantation of Bill 20}

Bill 20 is a response to a previous law on assisted reproduction passed in 2010, known as

Bill 26. Bill 26 mandated coverage for the medical costs, including physician visits, infertility assessments and treatment procedures, either in public or private clinics, of either six natural or three stimulated IVF cycles. Drug costs associated with the treatment of for instance, hormone stimulation, were added later, under the Health Insurance Act 2015.

Prior to the regulations added by Bill 20, access to coverage of ART was available to all women with a valid Quebec health card, without operationalization of "reproductive age," and without a confirmed diagnosis of infertility. For single women and same-sex couples, several failed IUIs, confirming infertility, must have first been performed for access to IVF. In the case for male individuals, including male same-sex couples, access to IVF with donor eggs and a surrogate was available without having to go through IUI if their egg donor was from a different individual than their potential surrogate.

Bill 26 had two main objectives: 1) to give infertile individuals an opportunity to have children, 2) to reduce neonatal costs and medical complications by reducing the rates of multiple pregnancies associated with ART by imposing a SET policy in IVF. It must be noted that Bill 26 was the first of its kind, and with its implementation, Quebec became the first jurisdiction in North America to fully-fund IVF. With an initial allotted budget of \$35 million per year, the Liberal government precisely planned to increase the number of live IVF births 
from 1000 to 1,500 infants per year, and to reduce the rates of multiple pregnancies associated with assisted procreation from 30\% to $10 \%$ (4). The hope at the time was that the savings on neonatal care associated with multiple births secondary to IUI would partially offset the cost of covering IVF.

\section{Factors that explain how and why Bill 20 was mandated How the topic of assisted reproduction came onto the government's agenda}

In June 2014, the Commission on Health and Well-Being in Quebec (acronym CSBE in French, for Commissaire à la Santé et au Bien-Être) published a report on the current costeffectiveness of assisted procreation. The Summary Advisory on Assisted Procreation in Quebec concluded that the government had met its goal in 1) to increase the number of live births through IVF from 1,000 to 1,300, and 2) to reduce the rate of multiple births from $30 \%$ to $10 \%$ with the new SET policy (4). However, despite a reduction in the number of multiple birth pregnancy rates, the predicted savings in neonatal intensive care unit (NICU) costs from assisted-reproduction associated births (both IUI and IVF-related) compared to spontaneous singleton conceptions were not met (4). No comparison of costs between NICU hospitalizations from IVF conceptions and spontaneous conceptions from a comparable period before Bill 26 was reported. Ultimately, the key findings were that the province's live-birth rate though increased by $1-2 \%$ per year since 2010 , it was associated with a cost of $\$ 63$ million per year, while the initial budget set for this goal was $\$ 35$ million (4).

In the report, it was suggested that births from ART may have continued to incur high costs due to greater number of women of AMA entering the program. Given that women of older age require more cycles of IVF, these were thought to be associated with higher rates of complex pregnancies and deliveries, as well as increased fertility drug costs compared to spontaneous singleton pregnancies. During the period between 2010-2013, though only 246 out of 1300 babies were born to women older than 40 years old, each of these live births cost over $\$ 45,000$. Thus, the Summary Advisory Report recommended that an age cap be set for women seeking subsidized ART (4). Other proposed recommendations following cost-analysis of the program included: clarifying the eligibility criteria, reevaluating the long-term viability of the program, and finally reconsidering the ethical and societal obligations to fund the program (4). Finally, the CSBE called for greater transparency regarding costs of assisted procreation and suggested that financial contribution be made by either individuals expecting a child through ART or those participating in ART services.

\section{How the decision was developed in Quebec}

The sitting government at the time, the Liberal Party of Quebec, introduced Bill 20, including their proposal to delist IVF, within the larger context of massive budgetary cuts across all government programs. Their agenda was supported by a report generated by the Auditor General that highlighted the astronomical costs of medical specialists' salaries in Quebec, igniting further controversy on the viability of the assisted procreation program: specialists had exceeded their allotted renumeration budget by \$384 million between 2010-2015 (6).

Overall, Bill 20 aimed to optimize the utilization of health services by improving access and continuity of care across the province, and in doing so, reduce the provincial debt (reaching $\$ 175.5$ billion by 2013), which was the largest of any province at the time (6). The government aimed to implement this policy by imposing minimum quotas on the number of patients general practitioners must register in their practice, as well as reducing the number 
of patients enrolled in a specialists' practices. However, the other aspect of Bill 20 was the delisting of IVF services, which was lumped into the larger context of the act, which may have eclipsed proper discussion about IVF delisting.

Several proposals from stakeholders attempted to alter the decision to delist IVF under Bill 20 following its initial proposal on 29 November 2014. Below are key attitudes by members of Quebec political parties in 2015 and representatives of the LGBT community, as well as the Quebec Infertile Couple's Association that spoke to the National Assembly.

Many Quebec opposition parties considered delisting IVF as part of numerous austerity measures. Ms. Dianne Lamarre, of the Parti Québécois, acting as the official opposition critic for health and access to care discussions on Bill 20, advocated for continued coverage for all services related to assisted procreation. Ms. Lamarre maintained her belief that fertility treatments are an essential medical service for Quebecers (7). She also believed recommendations from the $\mathrm{CSBE}$, such as clarifying eligibility and increasing transparency were not taken into consideration prior to de-funding IVF (7).

Ms. Francoise David from Québec Solidaire also voiced her concerns regarding Bill 20 at the National Assembly. Specifically, Ms. David argued that infertility is not a lifestyle choice, and therefore, funding for IVF should be covered by the Quebec government, including for transgender persons (8).

Ms. Mona Greenbaum, from the LGBT Council of Quebec, voiced her concerns about the ethics of using psychosocial assessments for screening parents or single women accessing ART given the lack of clarity on the government's part in defining the type of assessment. For instance, whether such assessments would be mandatory for all participants, and whether transgender and same-sex couples may be unfairly excluded (9). The use of psychosocial assessments in who could access IVF was later removed (discussed in Section 5.2).

Ms. Véronique Robert, a representative of the Association of Infertile Couples of Quebec, also spoke at the Bill 20 hearings. Ms. Robert emphasized that ART should be covered under the Quebec Health Insurance Plan as infertility is a medical condition (10).

Despite increasing pressure from opposition parties and IVF advocacy groups to maintain funding for ART services, the final decision to cut IVF was implemented on November 10th 2015.

\section{How reform was achieved}

\section{Amendments to the Law regarding Bill 20}

The enactment of, "An Act to enact the Act to Promote Access to Family Medicine and Specialized Medicine Services and to Amend various Legislative Provisions Relating to Assisted Procreation," also known as Bill 20, led to amendments in multiple laws, such as the Health Insurance Act, Research Activities Relating to Assisted Procreation, Prescription Drug Insurance Act, Régie de I'Assurance Maladie and An Act Respecting Health Services and Social Services (1).

\section{Implementation Plan}

The final provision changes were as follows following implementation of Bill 20:

- Women that initiated their IVF treatments prior to 10 November 2015 would continue to be covered until the end of their ovulatory cycle

- Embryo cryopreservation would be insured under the Health Insurance Act until 10 November 2018

- Fertile individuals would be insured for fertility preservation and retrieval services prior 
On 11 November 2015, the Quebec Ministry of Finance published an information report announcing tax credits to individuals utilizing ART. The government offered tax credits for SET depending on, 1) the income of the couple, 2) whether a member of the couple already had children, 3) if either parent had previously been voluntarily sterilized. The tax credit corresponds to a percentage of the expenses claimed, calculated on the basis of family income until one child was born. For instance, IVF treatment would be covered for families whose income was under $\$ 50,000$ and over $\$ 120,000$ to receive an $80 \%$ and $20 \%$ tax credit respectively for one cycle of IVF (12). The maximum tax credit is $\$ 16,000$.

The delisting of IVF treatments under Bill 20 coincided with absurd propositions that were poorly communicated and later ramified. For instance, the use of psychosocial assessments, including home visits, the complete barring of women over 42 years old to access IVF (publicly or privately) and uncertainty regarding access to assisted procreation for LGBT populations sparked controversy in the province and nationally. After discussion with members of the LGBTQ community, members of opposition political parties and media criticism, these aspects of the law were removed.

One way in which the government conveyed their new plan regarding assisted procreation was through their Portal on Health and Well-Being website (13). On this website, information is provided regarding assisted procreation services, eligibility and how and where to access them, (3).

\section{Impact of Bill 20 Following Implementation}

A surge in IVF services was observed among couples prior to Bill 20 assent on 10 November 2015. Six-months following legislation changes, the number of IVF cycles dropped from 750 to 250, beginning from January 2016 at the MUHC Reproductive Clinic (5).

Concerns by reproductive specialists have arisen since implementation of Bill 20. The first is that rates of IUI, a funded alternative to IVF, have been increasing (15). As a result, women are more likely to have multiple-birth pregnancies or are forced to terminate viable embryos (15). Indeed, the number of multiple birth pregnancies has risen to $10 \%$ from the previous $5 \%$ (15). Secondly, specialists speculate that a reduction in patients seeking IVF treatments may increase costs of ART in the future since fewer clients means less funds available to maintain staff and equipment at fertility centers (15).

Given that Bill 20 aimed to delist IVF services rather than implement new services, no new studies have been published since. However, Mr. Francois Legault, the current Premier from Coalition Avenir Quebec, stated in an election campaign interview that if elected, they would study whether covering one cycle of IVF for free by 2020 at a cost of $\$ 16$ million dollars was feasible (14). Some considerations regarding this potential policy would be the use of IVF only as a last resort, limiting a woman by her age, banning men who have had a vasectomy and reducing the cost of fertility medications (14).

Policy changes regarding assisted procreation in Quebec under Bill 26 and Bill 20 have been a model for other provinces in deciding whether to fully-fund or partially subsidize assisted procreation programs. While the Quebec government was deciding to delist their IVF services, Ontario announced in October 2015 that it would allot \$50 million dollars for IVF treatment. In its decision, given the strong correlation between age, cost and limited success among older women utilizing IVF, Ontario placed an age cap on women who can receive publicly funded IVF treatments: women must be under the age of 43 years old (16).

\section{Conclusions}


"An Act to promote access to family medicine and specialized medicine services and to amend various legislative provisions relating to assisted procreation," known as Bill 20, was passed on 10 November 2015 at the National Assembly of Quebec. In this bill, coverage for services related to IVF were delisted, with specific criteria for tax credits based on gross income. The decision to delist coverage for IVF followed the CBSE report indicating that the program cost $\$ 63$ million, with only 1300 live births per year. Despite strong opposition from opposing political parties, LGBT, as well as infertility group representatives, the decision to delist IVF treatments was passed. In 2017, the MUHC Reproductive Clinic reported a renewed rise in multiple birth pregnancies due to the consequential increase in the use of IUI treatments. Ultimately, while delisting the program fits in the broader provincial picture of balancing the budget, the lack of coverage for IVF services discriminates against those who cannot afford out-of-pocket expenses, and in fact may contribute to increased costs in maternal and infant hospitalizations.

\section{References}

1. Williams JW. Williams Obstetrics. 25th ed.: McGraw-Hill Education Medical; 2018.

2. An act to enact the act to promote access to family medicine and specialized medicine services and to amend various legislative provisions relating to assisted procreation (2015). < http://canlii.ca/t/52m54>

3. Programmes et mesures d'aide de services de procreation assiste. Portal of Health and Well-Being. Quebec Ministry of Health. 2018.

http://sante.gouv.qc.ca/en/programmes-et-mesures-daide/services-de-procreationassistee/recourir-aux-services-de-procreation-assistee

4. Blancquaert I, de Langavant, Cleret, Ganache, Isabelle. Summary Advisory on Assisted Reproduction in Québec. Commissaire à la santé et au bien-etre Quebec 2014.http://www.csbe.gouv.qc.ca/fileadmin/www/2014/Procreation_assistee/CSBE_PA_SummaryAdvisory_2014.pc

5. Hendry L. IVF treatments drop dramatically since Quebec funding cut 6 months ago: Canadian Broadcasting Corporation; 2016.

http://www.cbc.ca/news/canada/montreal/ivf-quebec-funding-1.3577865

6. Leclerc G. Report of the Auditor General of Quebec, Highlights. In: Assembly QN, editor. Quebec 2015.

7. Hequet C. La fin de la gratuite de la procreation medicalement assistee? Une injustice en sante? 2016.

8. David F. Journal des débats (Hansard) of the National Assembly. Quebec National Assembly. 41st Legislature. 1st Session.2014. http://www.assnat.qc.ca/en/travauxparlementaires/assemblee-nationale/41-1/journal-debats/20150513/146873.html

9. Greenbaum M. Committee on Health and Social Services Special consultations and public hearings on Bill 20. National Assembly of Quebec, 41st Legislature, 1st Session. 2015. http://www.assnat.qc.ca/fr/travaux-parlementaires/commissions/csss-411/journal-debats/CSSS-150318.html

10. Robert V. Special consultations and public hearings on Bill 20: Association canadienne de sensibilisation a I'infertilite (ACSI). Committee on Health and Social Services Special consultations and public hearings on Bill 20. 41th Legislature, 1st Session.: Quebec National Assembly; 2015. http://www.assnat.qc.ca/fr/travauxparlementaires/commissions/csss-41-1/journal-debats/CSSS-150317.html

11. Health Insurance Act, CQLR c A-29, (2011). http://canlii.ca/t/kwgj

12. Becoming a Parent : Services for Quebec Citizens. Quebec Government. Quebec Ministry of Finance. 2018. http://www4.gouv.qc.ca/EN/Portail/Citoyens/Evenements/DevenirParent/Pages/credt_impot_traitm_infer.aspx

13. Schwartz T. Fate of frozen embryos uncertain as Quebec moves to cut IVF program. CTV News. 2015. http://www.ctvnews.ca/health/fate-of-frozen-embryos-uncertain-asquebec-moves-to-cut-ivf-program-1.2287371

14. Feithe J. Quebec election: Restored IVF program would offer 1 free cycle, CAQ says: Montreal Gazette; 2018. https://montrealgazette.com/news/quebec-election-restored- 
ivf-program-would-offer-1-free-cycle-caq-says

15. Hendry L. Quebec's axing of fully funded IVF leads to increase in multiple pregnancies Canadian Broadcasting Corporation. 2017.

http://www.cbc.ca/news/canada/montreal/quebec-s-axing-of-fully-funded-ivf-leadsto-increase-in-multiple-pregnancies-1.4461148

16. Get Fertility Treatments. Governement of Ontario Health Department. Section 3.

Goverment of Ontario. 2017. https://www.ontario.ca/page/get-fertility-

treatments\#section-3

\section{(c) (1) (3)}

This work is licensed under a Creative Commons Attribution-NonCommercial-ShareAlike 4.0 International License.

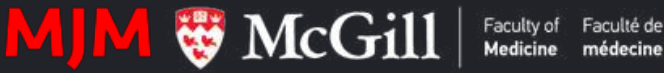

(C) McGill Journal of Medicine 2020

Electronic ISSN 1715-8125

\section{fy}

